\title{
The Effect of Broiler Breeder Ages on the Qualitive and Quantitive Properties of the Egg
}

\author{
Shahabodin Gharahveysi, Seyed Milad Farhadi Niaki and Mehrdad Irani \\ Department of Animal Science, Qaemshahr Branch, Islamic Azad University, Qaemshahr, Iran
}

Received 2012-03-22, Revised 2012-08-02; Accepted 2012-08-30

\begin{abstract}
Broiler breeder age is one of the most important factors that affects on egg properties. However by increasing the age of broiler breeder flock, the quality of eggs and consequently the quality of their chick products would be changed. In order to study the effect of broiler breeder flock age on the various aspects of chick products, 300 fertilizable eggs were selected randomly, from 3 broiler breeder farms. Selected eggs were collected from broilers that were 30 (young), 36 (peak), 43(after peak), 53 (old), 60 (very old) and 82 (molted) weeks old. Collected eggs were stored during 3 to 4 days in the ambient temperature. Qualitive and quantitive aspects of eggs including egg weight, albumen height yolk, height thickness of egg shell, yolk color, Albumen and yolk PH and Hugh unit were studied. Trait Analysis was done by ANOVA procedure of SAS statistical software. To compare the means, Duncan test was used. The effects of age and breeder farms on the egg weight, yolk color, yolk and albumen PH, yolk and albumen height, shell egg thickness and Hugh unit were significant $(\mathrm{p}<0.05)$. The lowest difference was seen between the age of 53, 60 and 82 week old $(\mathrm{p}<0.05)$. Albumen PH and alkaline is increased by increase of age, but yolk PH is the variance. Influence of age on the traits including yolk and albumen height and Hugh unit was decreased and the color of yolk was faded by increasing age. According to obtained results from these research performances of ages of 53, 60 and 82 weeks are close together. We could conclude that older broiler breeder flocks are produce the better qualitive and quantitive properties of egg products. Since most poultry enough information about the quality of breeder chickens and the best age to have chickens, using the results of this study can be answered many questions.
\end{abstract}

Keywords: Broiler Breeder Age, Eggs Weight, Eggs Shell Thickness, Hugh Unit, PH and Ross

\section{INTRODUCTION}

Bird's age is one of the natural effective factors on the daily product and quality of egg in a flock the size of eggs is elated not only to the weight, but also to the age. In the start of laying period, eggs hell thickness is very more than he end of product. By increasing age of broiler, eggs shell thickness is more thinned. Weak quality of the egg shell influences on the inner quality of eggs during laying or hatchery period . The most information about quality of egg shell, has achieved during last 50 years. In the meantime, poultry genetics, ration, installation and management have changed and improved significantly. Not only a factor causes to crack and weakness of eggs, but also, today, more factors have been known which affects on the Corresponding Author: Shahabodin Gharahveysi, Department of Animal Science, Qaemshahr Branch, Islamic Azad University, Qaemshahr, Iran quality of eggs. Some of the mentioned factors are included nutrient levels, diseases, managements, environment and modification of spices.

\section{MATERIAL AND METHODS}

In order to perform experiments, concerning to egg properties, 300 fertilizable eggs selected randomly, from 3 boiler breeder farms. Farms included Dorna Jouje Shomal, Dorna Jouje Delijan and Zarbal broiler breeder. In the Dorna Jouje Shomal farms elected eggs were collected from weeks 30 (young), 36 (peak) and 43 (after peak) chick. The average of the product in Dorna Jouje Shomal farm was $84,85.1$ and $75.5 \%$, respectively.

In Dorna Jouje elijan, the sampled eggs which were in the age of week 82 (molt) in the Zarbal Company, selected 
egg were sampled from chicks which were 53 (old) And 60 (very old) weeks. Averages of product at mentioned age were 67.29 and $59.65 \%$ collected eggs per 3-4 day, at room temperature. Then some of the normal eggs that must be set to hatchery were sending to Hatchery Company. Some of the eggs were sent to nutrition laboratory of the Islamic Azad University- Qaemshahr branch, in order to perform experiments related to the study of qualitive and quantitive properties of eggs. Total sampled eggs were measured by digital scale Sartorius (Model CPC 153) with 0.001gram accuracy and then recorded. The content of all eggs was emptied, individually, in the trays. Then egg inner characteristics including yolk and albumen height were weighted for trait of albumen height, most of upper of albumen was weighted that was located near of yolk and their yolk height from most upper part of yolk which were in the middle of yolk by caliper.

Accuracy of caliper were $2 \%$ millimeter. while testing, in some cases during breaking eggs, their yolk were cracked or their albumen was thin. These observations prove that some of the eggs were dated. After recording albumen height and egg weight by following formula, Hugh unit was calculated and recorded for each egg:

$$
\mathrm{HU}=100 \log \left(\mathrm{H}+7.57-1.7 \mathrm{~W}^{0.37}\right)
$$

Where:

$\mathrm{HU}=$ Hugh unit

$\mathrm{H}=$ Height of dense albumen to millimeter

$\mathrm{w}=$ Egg weight to gram

After breaking the eggs, their shells were separated. Then they were measured and recorded at 3 arts of head (thing part), intermediate and end of eggs (width part), by micrometer. The micrometers were more accurate than caliper. This investigation was done by micrometer (Model CMC) with 1\% millimeter accuracy. After eggs were cracked and their inner content was spread over a smooth surface (tray), yolk colors were measured by color of yolk (By kit of identifying yolk color Roche).

These kits were graded from number 1 to 15 and have linear relation with the amount of Xenophile (Dibazar et al., 2010). Colors of cart were adapted to yolk color and then nearest number to color of kit were recorded. Yolk and albumen $\mathrm{PH}$, after emptying contents of eggs on the tray were measured and recorded by $\mathrm{PH}$ meter. Recorded data were transferred to Excel software (2003), normal distribution test of data was done by SAS statistical software (2003) and then initial statistical information (Descriptive Statistic) was calculated.

Traits analysis was done by following statistical model and ANOVA procedure of SAS statistical software (with $95 \%$ precision):

$\mathrm{Y}_{\mathrm{ij}}=\mu+\mathrm{H}_{\mathrm{i}}+\mathrm{A}_{\mathrm{j}}+\mathrm{e}_{\mathrm{ij}}$

Where:

$\mathrm{y}_{\mathrm{ij}}=$ Amount of each observation for per trait

$\mu=$ Mean

$\mathrm{H}_{\mathrm{i}}=$ Effect of breeder farm

$\mathrm{A}_{\mathrm{j}}=$ Effect of boiler breeder age

$\mathrm{e}_{\mathrm{ij}}=$ Effect of errors

To compare the means, Duncan test was used.

\section{RESULTS}

Descriptive statistics of studied traits are presented at Table 1.

According to Table 2, there is no significant difference between the average of egg weight product in the Dorna Jouje Delijan and Zarbal broiler breeder farms ( $p>0.05$ ), but the difference between the average of egg weight product in these farms are significant $(p<0.05)$. The effect of the difference between the average of egg weight product by broiler breeders with age of 53, 60 and 82 weeks is not significant $(p>0.05)$. There is a significant difference between egg weights of 30,36 and 43 week $(p<0.05)$. The difference between the average of egg weight, broiler breeder of this 3 ages and the other ages is significant $(p<0.05)$. According to Table 2 , there is no significant difference between mean albumen height of egg product at Dorna Jouje Shomal and Delijan $(p>0.05)$, also the difference between mean albumen height of egg product at Dorna Jouje Deiljon and Zarbal is significant $(p>0.05)$. But inversely, difference between mean albumen height of egg product at Dorna Jouje Shomal and Delijan with Zarbal is significant $(p<0.05)$. Effect of difference between mean albumen height of egg product by broiler breeder age of 36, 53, 60 and 82 week old is not significant $(\mathrm{p}>0.05)$. There is also a significant difference between albumen height, broiler breeders at to latter age and another age $(p<0.05)$.

As shown in Table 2 , the difference between average of yolk height of egg product at Dorna Jouje Shomal and Zarbal is not significant $(p>0.05)$, but the difference of this at Dorna Jouje Shomel and Zarbal farms with Delijan farm is significant $(\mathrm{p}<0.05)$. 
Table 1. Descriptive statistic of the traits

\begin{tabular}{llrr}
\hline Trait (unit) & Number & Average & Cv\% \\
\hline Egg weight & 300 & 64.697 & 4.828 \\
Albumen height & 270 & 6.453 & 16.810 \\
Yolk height & 272 & 18.450 & 5.181 \\
Hugh unit & 270 & 77.339 & 10.614 \\
Egg shell 1 & 300 & 0.342 & 8.100 \\
Egg shell 2 & 300 & 0.333 & 7.602 \\
Egg shell 3 & 300 & 0.336 & 7.466 \\
Color of yolk & 300 & 7.120 & 8.208 \\
Yolk PH & 279 & 9.165 & 0.000 \\
Albumen PH & 281 & 7.068 & 3.575 \\
\hline
\end{tabular}

Table 2. Study the effect of breeder farms and various ages of broiler breeder on metric traits

\begin{tabular}{|c|c|c|c|c|}
\hline Treats & Egg weight & Albumen height & Yolk height & Hugh unit \\
\hline (1) & $61.310^{\mathrm{b}} \pm 0.255$ & $6.600^{\mathrm{a}} \pm 0.092$ & $18.060^{\mathrm{b}} \pm 0.081$ & $79.350^{\mathrm{a}} \pm 0.701$ \\
\hline (2) & $67.880^{\mathrm{a}} \pm 0.441$ & $6.510^{\mathrm{ab}} \pm 0.161$ & $19.930^{\mathrm{a}} \pm 0.142$ & $76.410^{b} \pm 1.223$ \\
\hline (3) & $68.160^{\mathrm{a}} \pm 0.312$ & $6.190^{\mathrm{a}} \pm 0.115$ & $18.290^{\mathrm{a}} \pm 0.100$ & $74.670^{\mathrm{b}} \pm 0.875$ \\
\hline \multicolumn{5}{|c|}{ Age (week) } \\
\hline 30 & $57.970^{\mathrm{d}} \pm 0.441$ & $7.620^{\mathrm{a}} \pm 0 / 153$ & $18.730^{\mathrm{b}} \pm 0.135$ & $87.290^{\mathrm{a}} \pm 1.160$ \\
\hline 36 & $61.320^{\mathrm{c}} \pm 0 / 441$ & $6.510^{\mathrm{b}} \pm 0 / 163$ & $18.030^{\mathrm{c}} \pm 0.144$ & $79.470^{\mathrm{b}} \pm 1.230$ \\
\hline 43 & $64.660^{\mathrm{b}} \pm 0.441 \quad 5.490^{\mathrm{c}} \pm 0 / 165$ & \multicolumn{3}{|c|}{$300^{\mathrm{d}} \pm 0.145 \quad 69.990^{\mathrm{d}} \pm 1.251$} \\
\hline 53 & $68.440^{\mathrm{a}} \pm 0.441$ & $6.250^{\mathrm{b}} \pm 0 / 169$ & $18.720^{\mathrm{b}} \pm 0.144$ & $75.190^{c} \pm 1.282$ \\
\hline 60 & $67.890^{\mathrm{a}} \pm 0.441$ & $6.140^{\mathrm{b}} \pm 0 / 158$ & $17.890^{\mathrm{c}} \pm 0.140$ & $74.210^{\mathrm{c}} \pm 1.197$ \\
\hline 82 & $67.880^{\mathrm{a}} \pm 0.441$ & $6.510^{\mathrm{b}} \pm 0 / 161$ & $19.930^{\mathrm{a}} \pm 0.142$ & $76.410^{\mathrm{cb}} \pm 1.223$ \\
\hline MSE & 9.750 & 1.170 & 0.910 & 67.380 \\
\hline$\% \mathrm{CV}$ & 4.820 & 16.810 & 5.180 & 10.610 \\
\hline
\end{tabular}

(1): Dorna Jouje Shomal, (2): Dorna Jouje Delijan, (3): Zarbal company, * similar letters at each column show statistical in difference at $\% 5$ level

Table 3. The effect of chick farm and various ages of broiler breeder on the trait of shell thickness

\begin{tabular}{llll}
\hline Treat & Egg shell1 & Egg shell 2 & Egg shell 3 \\
\hline$(1)$ & $0.350^{\mathrm{b}} \pm 0.002$ & $0.342^{\mathrm{a}} \pm 0.002$ & $0.347^{\mathrm{a}} \pm 0.002$ \\
$(2)$ & $0.359^{\mathrm{a}} \pm 0.004$ & $0.349^{\mathrm{a}} \pm 0.004$ & $0.350^{\mathrm{a}} \pm 0.004$ \\
$(3)$ & $0.320^{\mathrm{c}} \pm 0.002$ & $0.310^{\mathrm{b}} \pm 0.003$ & $0.310^{\mathrm{b}} \pm 0.003$ \\
Age (week) & & & \\
30 & $0.371^{\mathrm{a}} \pm 0.004$ & $0.366^{\mathrm{a}} \pm 0.004$ & $0.374^{\mathrm{a}} \pm 0.004$ \\
36 & $0.350^{\mathrm{b}} \pm 0.004$ & $0.345^{\mathrm{b}} \pm 0.004$ & $0.35^{\mathrm{b}} \pm 0.004$ \\
43 & $0.331^{\mathrm{c}} \pm 0.004$ & $0.314^{\mathrm{c}} \pm 0.004$ & $0.319^{\mathrm{c}} \pm 0.004$ \\
53 & $0.320^{\mathrm{d}} \pm 0.004$ & $0.314^{ \pm} \pm 0.004$ & $0.309^{\mathrm{c}} \pm 0.004$ \\
60 & $0.320^{\mathrm{c}} \pm 0.004$ & $0.307^{\mathrm{c}} \pm 0.004$ & $0.310^{\mathrm{c}} \pm 0.004$ \\
82 & $0.360^{\mathrm{ab}} \pm 0.004$ & $0.349^{\mathrm{b}} \pm 0.004$ & $0.35^{\mathrm{b}} \pm 0.004$ \\
MSE & 0.001 & 0.001 & 0.001 \\
\%CV & 8.090 & 7.600 & 7.46 \\
\hline
\end{tabular}

(1): Dorna Jouje Shomal, (2): Dorna Jouje Delijan, (3): Zarbal Company, *Similar letters at each column show lack of statistical difference at $\% 5$ level

At Table 2, there is no difference between mean of Hugh unit and egg product at Dorna Jouje Delijan and Zarbal farms $(p>0.05)$, but the difference of them at Dorna Jouje Delijan and Zarbal with Dorna Shomel is significant $(p<0.05)$. The effect of the difference between these factors by broiler breeder at age 53,60 and 82 week and also between the age of 36 and 82 week is not significant $(\mathrm{p}>0.05)$.

There is a significant difference between the average of Hugh unit and egg of 30,36 and 43 week $(p<0.05)$. There is a significant difference between Hugh unit and broiler breeder of three ages and another age, too $(\mathrm{p}<0.05)$. 
As shown at Table 3 , to evaluate this trait, from 3 part head (thin part), inter mediate and bottom (width apart) of the eggs were used and data were investigated individually, that according to Table 3, there was a significant difference between Dorna Jouje Shomal, Dorna Jouje Delijan and Zarbal $(p<0.05)$. The effect of various ages on this trait, show that ages between 43 and 60 weeks, between 30 and 82 weeks and 36 and 82 weeks had no significant differences ( $\mathrm{p}>0.05$ ).

Between the ages of 36 and 53 weeks on one hand and with above mentioned ages on the other hand had significant difference $(p<0.05)$. Table 3 showed that there is no significant difference between Dorna Jouje Shomal and Delijan $(p>0.05)$. But both of them had a significant difference compared to Zarbal $(p<0.05)$. Effect of various ages on this trait showed that age of 43, 53 and 60 weeks and age of 36 and 82 have no significant differences $(p>0.05)$, however ages of 30 weeks are significantly different from all ages and above mentioned ages $(p<0.01)$. According to Table 3, there is no significant difference for width part of eggs between farms of Dorna Jouje Shomal and Delijan $(p>0.05)$. But both of them had a significant difference with Zarbal farm $(p<0.05)$. All studies on the various ages of broiler breeder, showed that ages of 43,53 and 60 week and 36 and 82 weeks had no significant difference $(p>0.05)$. However there is significant difference between the age of 30 week with another ages and mentioned above ages $(\mathrm{p}<0.05)$.

According to Table 4, code number 7 for Dorna Jouje Shomal farm with the most numbers equal to 79 eggs, followed by Zarbal farm with 56 numbers, had the most numbers in color code of number 7. Color code 6 for Dorna Jouje Shomal farm was zero and color code 9 of yolk for Zarbal farm was zero, too.

The effect of difference between various ages for yolk color by code number 8 at ages of 30,82 and also for code number 9 at ages of 36, 43, 53 and 60 was zero. Color code of number 7 for various ages has most numbers against another code.

Table 5 shows that there is a significant difference between average of albumen PH of egg product at Dorna Jouje Shomal and Delijan and Zarbal $(p<0.05)$. But the effect of the difference between this factor by broiler breeder at ages of 43 and 82 weeks and also ages of 36 and 53 weeks is not significant ( $>>0.05)$. Thus this difference is significant between albumen $\mathrm{PH}$, broiler breeder at age of 30 and 60 weeks together and with others ages $(\mathrm{p}<0.05)$.

As, it was observed in Table 5, The difference between the average of yolk PH of egg product at Dorna Jouje Shomel and Dorna Jouje Delijon with Zarbal is significant $(p<0.05)$. The effect of difference between this factor by broiler breeder at age of 30 and 36 weeks and 43 and 82 weeks is not significant $(p>0.05)$. There is significant difference between this factor by broiler breeder at age of 53 and 60 together and with another weeks, too $(p<0.05)$.

Table 4. Statistical status of yolk color trait at breeder farmsand various ages of broiler breeder

\begin{tabular}{|c|c|c|c|c|c|}
\hline \multirow{2}{*}{$\begin{array}{l}\text { Yolk color } \\
\text { Factors }\end{array}$} & \multirow[b]{2}{*}{ Number } & \multicolumn{4}{|c|}{ Color cod } \\
\hline & & 6 & 7 & 8 & 9 \\
\hline (1) & 150 & 24 & 79 & 37 & 10 \\
\hline (2) & 50 & 0 & 31 & 17 & 2 \\
\hline (3) & 100 & 31 & 56 & 13 & 0 \\
\hline \multicolumn{6}{|l|}{ Áge (week) } \\
\hline $30^{\circ}$ & 50 & 0 & 22 & 18 & 10 \\
\hline 36 & 50 & 4 & 32 & 14 & 0 \\
\hline 43 & 50 & 20 & 25 & 5 & 0 \\
\hline 53 & 50 & 7 & 31 & 12 & 0 \\
\hline 60 & 50 & 24 & 25 & 1 & 0 \\
\hline 82 & 50 & 0 & 31 & 17 & 2 \\
\hline
\end{tabular}

Table 5. The effect of breeder farmsand various ages of broiler breeder on traits of albumen $\mathrm{PH}$, yolk $\mathrm{PH}$

\begin{tabular}{lll}
\hline Treat & Albumen PH & Yolk PH \\
\hline$(1)$ & $8.650^{\mathrm{c}} \pm 0.004$ & $6.580^{\mathrm{c}} \pm 0.021$ \\
$(2)$ & $9.030^{\mathrm{b}} \pm 0.011$ & $6.990^{\mathrm{b}} \pm 0.035$ \\
$(3)$ & $10.004^{\mathrm{a}} \pm 0.006$ & $7.860^{\mathrm{a}} \pm 0.026$ \\
Age (week) & & \\
30 & $8.740^{\mathrm{c}} \pm 0.011$ & $6.540^{\mathrm{c}} \pm 0.036$ \\
36 & $8.240^{\mathrm{d}} \pm 0.011$ & $6.210^{\mathrm{c}} \pm 0.035$ \\
43 & $9.070^{\mathrm{b}} \pm 0.014$ & $7.070^{\mathrm{b}} \pm 0.039$ \\
53 & $8.270^{\mathrm{b}} \pm 0.013$ & $6.330^{\mathrm{d}} \pm 0.038$ \\
60 & $11.620^{\mathrm{a}} \pm 0.012$ & $9.330^{\mathrm{a}} \pm 0.034$ \\
82 & $9.030^{\mathrm{b}} \pm 0.011$ & $6.99^{\mathrm{b}} \pm 0.035$ \\
MSE & 0 & 0.063 \\
\%CV & 0 & 3.57 \\
\hline *Similar letters at each column show of statistical difference at \\
\%5 level
\end{tabular}

\section{DISCUSSION}

In this study, effect of breeder farms and various ages for traits such as eggs weight, yolk and albumen height, Hugh unit, egg shell thickness, yolk color, yolk and albumen $\mathrm{PH}$ were investigated. According to the findings of this research there were the lowest significant differences between of Dorna Jouje Delijon and Zarbal farms, while most significant differences were between Dorna Jouje Shomal and other farms.

The effect of difference between the averages of product trait by broiler breeders at ages of 53, 60 and 82 weeks had the lowest significance, however most of differences were between the averages of product trait at age of 30, 36 and 43 weeks. Similar experiments were carried out in accordance with this research which some of them have shown same results.

Researchers found that by increasing the age, of broiler breeder, the ratio of yolk weight to albumen weight would be increased. Scientists, in a study, found that young broiler breeders have lowest egg weight. However their finding showed that the egg weight, yolk 
and albumen weight were increased by increase of age. In the studies, the effect of increasing age on decreasing albumen is reported. Through check the effect of age on the trait of albumen height they found that is increasing the age makes the albumen height decreased and lowest height was related to age of 43 week whereas lowest height of albumen was observed at Zarbal Company. The results showed that by increasing the age, egg weight is increased, so the heaviest weight has been seen at the age of 53 weeks that was related to Zarbal farm.

The effects of the age on the yolk height trait showed that by increasing age, height of yolk is increased and the lowest heights have been seen at 43 weeks in Dorna Jouje Shomal farm. Relations were observed between egg weight and weight of chick product (Atlan et al., 1995; Constantini and Panella, 1984; Tservi-Gousi, 1987). Results of studies which investigated the effect of broiler age on the size of egg and albumen $\mathrm{PH}$, demonstrate that by increasing the age, egg size is increased, but no change was observed in albumen $\mathrm{PH}$.

Inversely, at other research, contrary results have been reported, for example albumen $\mathrm{PH}$ as increased by increasing the flock age. By increasing age of broiler breeder, the amount of PH albumen has been increased and most PH was observed at the age of 53 weeks and at egg product by Zarbal farm. By increasing the age, egg shell thickness would be decreased (Choi et al., 1983; Poyraz, 1989; Stadelman, 1986), there is a positive correlation between egg weight, shell weight and its thickness (Faaooq et al., 2001; Tyler, 1961) also; there is relation between quality of egg shell and its thickness (Choi et al., 1983; Poyraz, 1989; Stadelman, 1986).

\section{COCLUSION}

The effect of increasing age on decreasing the egg shell thickness is confirmed at this research, as if by increasing the shell thickness, amount of egg product is decreased and the lowest thickness in the age of 60 weeks which was related to egg product of Zarbal Company, was observed.

According to obtained results from this research lowest significant difference was between ages of 53, 60 and 82 weeks in which we could conclude that older broiler breeder flocks, better qualitive and quantitive properties of egg products. But for traits including shell thickness and Hugh unit, reversed reports were observed.

\section{ACKNOWLEDGEMENT}

Researchers of this study thanks a lot for efforts of hard-working personnel's who work at Dorna Jouje
Shomal broiler breeder (engineer Mr. Marzban), Mehregan Hatchery Company (Mr. Faraji), Zarbal Company (Mr. Akbarian). Manager of laboratory of animal and poultry nutrients of Azad Islamic University of Qaemshahr (Mr. Mohammadian) and Mr, Roodgar Amoli and engineer kamali.

\section{REFERENCES}

Atlan, O., I. Oguz and P. Settar, 1995. Japon bildircinlarinda yumutra agirlik ile ozgul agirligin kulucka ozelliklerine etkileri. Turk. J. Agric., For., 19: 219-222.

Choi, J.H., W.J. Kang and D.H. Baik, 1983. A study on some characteristics of fractions and shell quality of the chicken egg. Korean. J. Anim. Sci., 25: 651-655.

Constantini, F. and F. Panella, 1984. Correlations between egg weight and broiler performance. Anim. Breed Abst., 51: 35-40.

Dibazar, A.A., H.O. Park and T.W. Berger, 2010. Nonlinear dynamic modeling of impaired voice. Proceedings of the Annual International Conference of the IEEE Engineering in Medicine and Biology Society, Aug. 31-Sept. 4, IEEE Xplore Press, Buenos Aires, pp: 2770-2773. DOI: 10.1109/IEMBS.2010.5626361

Faaooq, M., M.A. Mian, M. Ali, F.R. Durrani and A. Asghar et al., 2001. Egg traits of fayumi birds under subtropical conditions. Sarhad. J. Agric., 17: 141-145.

Poyraz, O., 1989. Kabuk Kalitesi ile ilgili yumurta ozellikleri arasindaki fenotipik korelasyonlar. J. Lalahan Livest. Res. Inst., 29: 66-79.

Stadelman, W.J., 1986. The Preservation of Quality in Shell Eggs. In: Egg Science and Technology, Stadelman, W.J. and O.J. Cotteril (Eds.)., Avi Publishing Com Inc. Westport, Connecticut, USA.

Tservi-Gousi, A.S., 1987. Relationship between parental age, egg weight and hatching weight of Japanese quail. Br. Poult. Sci., 28: 749-752. PMID: 3446342

Tyler, C., 1961. Shell strength: Its measurement and its relationship to other factors. Br. Poult. Sci., 2: 3-19. DOI: $10.1080 / 00071666109382385$ 